\title{
Studies on dietary pattern of seleceted dibetic subjects of Parbhani city in Maharashtra
}

\author{
Rupali Shinde and Asha Arya
}

Diabetes is one of the most challenging non-communicable health problems in the twenty first century. Non-communicable diseases (NCD), also known as chronic diseases include cardiovascular diseases, diabetes, stroke, most forms of cancers and injuries. Such diseases mainly result from lifestyle related factors such as unhealthy diet, lack of physical activity and tobacco use. Hence, study was conducted with an objective to determine the socio-economic status, information about diabetes and food and nutrient intake of diabetics. Thirty non-insulin dependent diabetic subjects (men and women) were selected from Parbhani city of Maharashtra state. Information regarding their socio-economic status, duration and history about diabetes and food consumption pattern etc. was collected. The information regarding their dietary habits, frequency of consumption of different food groups in a day etc. were collected. The actual food intake of the selected diabetic subjects was collected for the immediate past 24 hours. The intake of different nutrients per day by each selected subject was then calculated from the food intake values using food composition tables. Food and nutrient adequacy was calculated based on balanced diets and recommended dietary allowances, respectively. It was observed that subjects were more diabetic subjects from 50-60 years age group 63.33 per cent, respectively. Sex wise data indicated that more number of male were sufferers of diabetes $(53.33 \%)$. Maximum subjects were from nuclear families $(60 \%)$. Diabetes was observed more among the subjects who were engaged in the service (36.66 \%). The income wise distribution indicated that there was increase in the number of subjects as the income was increased. Among them forty per cent were suffering from more than five years and 33.33 per cent subjects were suffering from $3-5$ years and few of them having family history of diabetes. These results clearly show that protein, energy, iron and fibre intake was lower than the RDA of ICMR among both these subjects. While fat consumption exceeded than RDA given by ICMR. It can be concluded that diabetes cannot be cured but it can be well controlled by modification in the diet and lifestyle.

Key Words : Diabetes, Socio-economic status, Diet history, Food intake, Nutrient intake

How to cite this article : Shinde, Rupali and Arya, Asha (2020). Studies on dietary pattern of seleceted dibetic subjects of Parbhani city in Maharashtra. Food Sci. Res. J., 11(2): 175-180, DOI : 10.15740/HAS/FSRJ/11.2/175-180.Copyright@ 2020: Hind AgriHorticultural Society. 